\title{
An automated walk-over weighing system as a tool for measuring liveweight change in lactating dairy cows
}

\author{
R. A. Dickinson, ${ }^{\star} \dagger$ J. M. Morton, $\ddagger$ D. S. Beggs, ${ }^{*} \dagger$ G. A. Anderson, ${ }^{*}$ M. F. Pyman, ${ }^{*}$ P. D. Mansell, ${ }^{* 1}$ \\ and C. B. Blackwood† \\ *University of Melbourne, 250 Princes Hwy., Werribee 3030, Australia \\ †Warrnambool Veterinary Clinic, 514 Raglan Parade, Warrnambool 3280, Australia \\ †Jemora Pty. Ltd., PO Box 2277, Geelong 3220, Australia
}

\section{ABSTRACT}

Automated walk-over weighing systems can be used to monitor liveweights of cattle. Minimal literature exists to describe agreement between automated and static scales, and no known studies describe repeatability when used for daily measurements of dairy cows. This study establishes the repeatability of an automated walk-over cattle-weighing system, and agreement with static electronic scales, when used in a commercial dairy herd to weigh lactating cows. Forty-six lactating dairy cows from a seasonal calving, pasture-based dairy herd in southwest Victoria, Australia, were weighed once using a set of static scales and repeatedly using an automated walk-over weighing system at the exit of a rotary dairy. Substantial agreement was observed between the automated and static scales when assessed using Lin's concordance correlation coefficient. Weights measured by the automated walkover scales were within $5 \%$ of those measured by the static scales in $96 \%$ of weighings. Bland and Altman's 95\% limits of agreement were -23.3 to $43.6 \mathrm{~kg}$, a range of $66.9 \mathrm{~kg}$. The $95 \%$ repeatability coefficient for automated weighings was $46.3 \mathrm{~kg}$. Removal of a single outlier from the data set increased Lin's concordance coefficient, narrowed Bland and Altman's $95 \%$ limits of agreement to a range of 32.5 $\mathrm{kg}$, and reduced the $95 \%$ repeatability coefficient to $18.7 \mathrm{~kg}$. Cow misbehavior during walk-over weighing accounted for many of the larger weight discrepancies. The automated walk-over weighing system showed substantial agreement with the static scales when assessed using Lin's concordance correlation coefficient. This contrasted with limited agreement when assessed using Bland and Altman's method, largely due to poor repeatability. This suggests the automated weighing system is inadequate for detecting small liveweight differences in individual cows based on comparisons

Received December 23, 2012.

Accepted April 2, 2013.

${ }^{1}$ Corresponding author: pmansell@unimelb.edu.au of single weights. Misbehaviors and other factors can result in the recording of spurious values on walk-over scales. Excluding outlier weights and comparing means of 7 consecutive daily weights may improve agreement sufficiently to allow meaningful assessment of small short-term changes in automated weights in individuals and groups of cows.

Key words: dairy, cattle, weight, scale

\section{INTRODUCTION}

Australian dairy cows commonly have radio frequency identification (RFID) microchip ear tags that allow identification using a microchip reader. The use of RFID has led to the development of a multitude of on-farm dairy infrastructure systems based on identifying cows as they walk into or out of the dairy. Such systems are becoming increasingly common in Australian dairy herds, with typical features including the individual control of feed levels in the dairy and various measurements of milk yield and quality.

Body condition score has been used as a noninvasive tool for assessing the degree of fatness of dairy cows, and repeated BCS assessments have been used to indirectly monitor weight change and energy balance, therefore aiding in the nutrition management of herds (Garnsworthy et al., 2008). Many studies have reported that dairy cattle commonly lose body condition for a period after calving, and the extent of postpartum body condition loss has been associated with reduced fertility (Morton, 2003; Roche et al., 2007b), reduced production (Berry et al., 2007a), occurrence of mastitis (Berry et al., 2007c), uterine infection, metabolic diseases (Roche et al., 2009), dystocia, and stillbirth (Berry et al., 2007b). However, limitations exist for BCS; for example, it is subjective (Maltz, 1997; Maltz et al., 1997), it requires an experienced visual assessor, variation exists between different assessors, and BCS changes only reflect external adipose loss (Macdonald et al., 1999). Whereas BCS assessment is a useful tool, automated weighing technology may provide an objective, more 
sensitive, less labor-intensive method for monitoring liveweight change (Roche et al., 2007a), allowing easier recognition of animals at risk of disease or reduced reproductive performance and improved management at the herd level (Maltz, 1997; Maltz et al., 1997).

Commercially available walk-over scales in combination with RFID technology can identify and record the liveweight of cattle as they traverse a weighing platform and can measure weights of dairy cattle twice daily as they enter or exit the dairy for milking. van Straten et al. (2009) suggested that if automated BW data collection systems were available on farm, BW loss monitoring could be routinely used as a management tool. A paucity of literature exists to describe the accuracy and repeatability of these systems when used in commercial dairy herds. To our knowledge, Alawneh et al. (2011) is the only published study describing the agreement between an automated weighing system and static scales. In that study, weight records from a pasture-fed herd in New Zealand demonstrated excellent agreement with static scales. However, in further studies, biologically implausible outlier weight measurements had to be cleaned to assess the effects of lameness on weight change (Alawneh et al., 2012a) and the effects of weight change on reproductive performance (Alawneh et al., $2012 b)$.

If automated weighing systems are to become an important dairy management tool, it is necessary to understand the agreement of such weighing systems to static scales, and to describe the repeatability and the frequency and etiology of outlier weights. This paper describes the repeatability of an automated walk-over weighing system and the agreement with static electronic scales when used in a commercial dairy herd to weigh lactating cows.

\section{MATERIALS AND METHODS}

This study was conducted in Australia on a typical southwest Victorian seasonal-calving dairy herd, where approximately 600 Holstein Friesian and Holstein Friesian $\times$ Jersey crossbred cows were milked twice daily in a 50-bale rotary dairy. The dairy had a set of commercially available automated walk-over scales (Tru-test XR3000 WOW Scales, Tru-Test Pty Ltd., Sunnybank, Australia) permanently installed in the exit race of the rotary dairy. All cows in the herd were fitted with RFID ear tags that were read at the exit to the automated scales. As cows traverse the weighing platform, liveweight, cow ID, and time of weighing were automatically recorded by the milking system software (Jantec Systems, Breakwater, Australia).

These walk-over scales were compared with a set of portable electronic static scales on which a weight was not recorded until the animal was stationary (Trutest AG500, Tru-Test). Prior to the study, both the automated and static scales were calibrated by placing 5 plastic 20-L containers (Redene Iodophor Teat Dip and Spray, DASCO Pty. Ltd., Heidelberg Heights, Australia) on each of the weighing platforms. Each set of scales was initially tared with the empty containers then all containers were filled to the full level with water and calibrated to $100.0 \mathrm{~kg}$.

Forty-six mid-lactation dairy cows (13 first lactation heifers, 10 cows aged $3-5 \mathrm{yr}$, and 23 cows $>5$-yr-old) were randomly drafted - every 14th cow in the herd was selected in order of milking - to give a subpopulation of animals with a range of weights $(364-696 \mathrm{~kg})$ that was likely to be representative of the main herd. These cows were then loaded onto the rotary milking platform before being weighed while walking over the automated scales. This was repeated 3 times within a 1-h period. Cows were then weighed once while standing still on the static scales. For the purposes of this experiment, the static scales were assumed to measure the true weights.

Each of 3 possible automated weights was compared with the single static weight for the same cow to assess the agreement between the automated and static scales. Repeatability of the automated scales was assessed using each cow's 3 automated weights.

To assess effects of cow behavior, each cow was observed traversing the walk-over weighing platform and any behavior associated with an abnormal crossing was noted and termed misbehavior. Misbehaviors observed during the study and considered to cause spurious readings included fast or frantic passage, another cow on the scale at the same time, or heavy stepping.

\section{Definitions}

Definitions for accuracy, agreement, precision, and repeatability are multiple and controversial. To provide clarity for interpretation of findings from statistical tests in this paper, definitions have been provided.

Accuracy is the degree of (systematic) bias (Lin, 2008); when static scale weights are plotted against automated weights, the closeness of the line of best fit to the $45^{\circ}$ line (slope of 1 ) through the intercept; imperfect accuracy can be due to the line of best fit slope deviating from 1 and being shifted upwards or downwards (Lin, 1989). Agreement is the degree to which scores or ratings are identical (Kottner et al., 2011); in this case, the degree to which each automated weight and the static scale weight for the same cow are identical; for continuous data, such as cow weights, it is the combination of accuracy and precision (Lin, 1989). Precision is how far observations deviate from the line of best 
fit (Lin, 1992). Repeatability is the extent to which replicate measurements in identical circumstances of a particular technique or instrument or observer are the same (Petrie and Watson, 2006); in this case, the degree of similarity of repeated automated weighings of the same cow.

\section{Data Analyses}

Differences, automated weight minus static weight, were calculated and expressed as percentages of the static weight. Lin's concordance correlation coefficients were calculated to assess the extent of agreement between the automated and static scales (Lin, 1989; Lin, 2000). Suggestions for interpretation of Lin's concordance correlation coefficient are almost perfect agreement (>0.99); substantial agreement (>0.95-0.99); moderate agreement $(0.90-0.95)$; and poor agreement $(<0.90 ;$ McBride, 2005, 2007).

Agreement was also assessed using the $95 \%$ limits of agreement and the range within which $95 \%$ of differences in weights between the automated and static scales lie was estimated (Bland and Altman, 1986, 1999). To assess whether differences between automated and static scale weights were clustered by cow, intraclass correlation coefficients for differences were calculated. Associations between differences and the mean of automated and static weight were also analyzed (Bland and Altman, 1990).

Repeatability was assessed using the $95 \%$ repeatability coefficient (Bland and Altman, 1999). This was defined as $1.96 \times(\sqrt{2}) \times \mathrm{Sw}$, where $\mathrm{Sw}$ is the square root of the residual mean square from a one-way ANOVA with cow as the factor. This describes the range within which $95 \%$ of the differences between 2 automated weight readings from the same cow would be expected to lie. Differences between 2 automated weights in the same individual were also calculated and expressed as percentages of the average of the 2 automated weights.

Limits of agreement and Lin's concordance correlation coefficients were calculated using the concord command in Stata 12.1 (StataCorp, College Station, TX), and intraclass correlation coefficients were calculated using xtreg, also in Stata 12.1. WinPepi 11.25 (www. brixtonhealth.com) was used to calculate repeatability coefficients. Grubbs' test (Grubbs, 1969) was used to define an outlier as implemented in MedCalc 12.4.2.1 (MedCalc software, Ostend, Belgium).

To assess practical uses of the scales for measuring liveweight change, errors in changes in automated weights for the same cow $(\mathrm{s})$ relative to the actual weight change were estimated by simulation using Excel (version 2007, Microsoft, Redmond, WA) with the @RISK for Excel add-in (version 5.5.1, Palisade Corporation,
Ithaca, NY). The simulations used the observed distribution of differences between automated and static weights to assess the errors when the scales are used to identify weight change based on changes between 2 individual automated weights for the same cow, changes between 2 means of 7 weights for the same cow, and mean changes for groups of cows. The distribution of differences between a single automated system weight and the cow's actual weight was assumed to follow a log-logistic distribution with location, shape, and scale parameters of $-47.446,55.947$, and 11.597 , respectively. This distribution was based on the observed differences between each automated system weight and static weight for the 127 cow weighings; it had the lowest chisquared goodness of fit statistic of 12 distribution types assessed using @RISK's distribution fitting routine. Errors were simulated using 2,000 iterations.

\section{RESULTS}

The automated weighing system did not record a weight every time a cow traversed the weighing platform. Possible causes for missing automated weights include failure of the RFID ear tag reader to identify the cow, passage of a cow over the scales at excessive speed, or close proximity to another cow. Of the 46 cows weighed, 37 cows yielded 3 out of 3 automated readings, 7 cows yielded 2 readings, and 2 cows only produced 1 automated weight, giving a total of 127 automated weights from a possible 138 readings. At first, second, and third weighings, $85 \%$ (39), 93\% (43) and $98 \%$ (45), respectively, of the 46 cows had weights recorded by the automated weighing system.

\section{Agreement}

Differences between automated weights and static weights are demonstrated in Figure 1. Automated weights differed by $10 \mathrm{~kg}$ or less from the static weight for $55.9 \%$ of weights; and by more than $20 \mathrm{~kg}$ for $9.4 \%$ of weights. Over all 127 automated weighings, the mean difference (automated weight minus static weight) was $10.1 \mathrm{~kg}(\mathrm{SD}=17.1 \mathrm{~kg})$.

Automated weights differed by less than $5 \%$ from the static weight for $96.1 \%$ of weights, with almost $100 \%$ of automated weight differences falling between $<5$ and $>10 \%$ of the static weight. Variation of automated weights from the static weight is plotted by cow in Figure 2. No obvious association was observed between difference and static weight.

Lin's concordance correlation coefficient was calculated to assess agreement between each of the 3 automated weighings and the static weight. These coefficients ranged from 0.91 to 0.99 and are further 


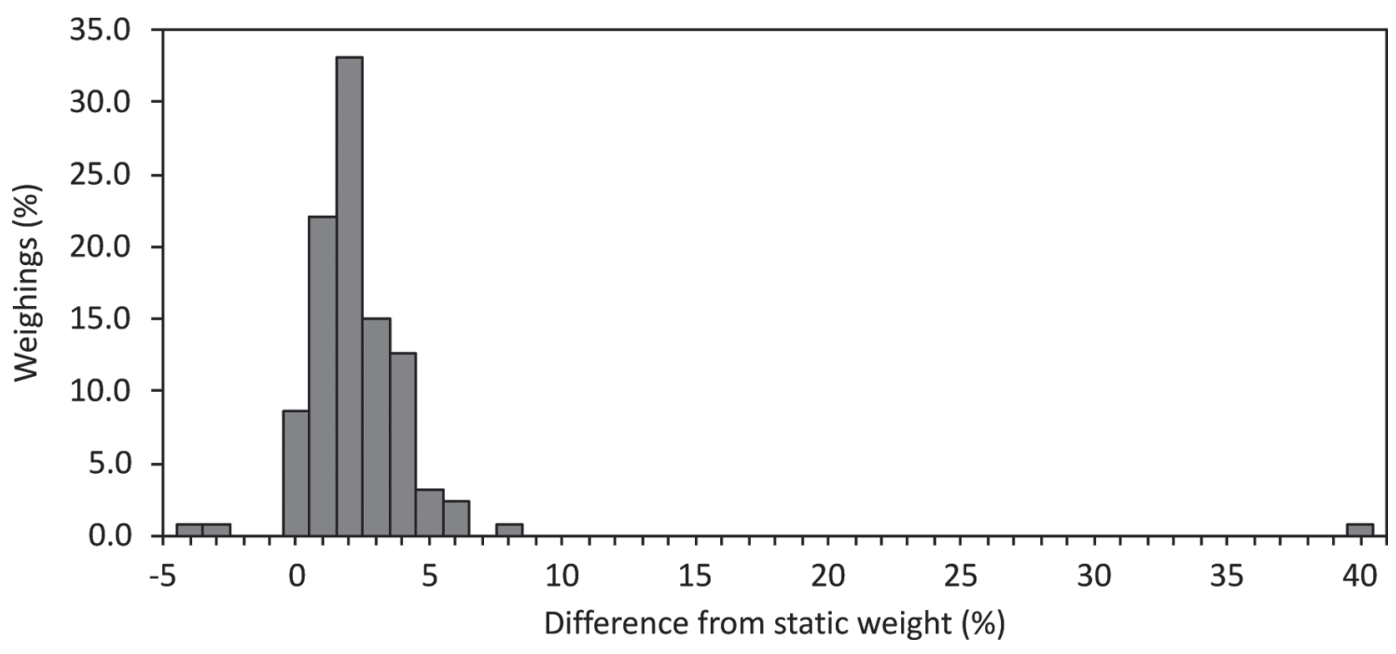

Figure 1. Differences between automated and static weights for 127 automated weighings of liveweight in 46 dairy cows.

described in Table 1. Table 2 shows that Lin's concordance correlation coefficients, and its 2 components (accuracy and precision) were high at all 3 weighings. A single automated outlier weight was identified where the difference between the weight measured at the first automatic weighing $(630 \mathrm{~kg})$ was far in excess of that measured by the static scales $(453 \mathrm{~kg})$ for 1 individual. This difference of $177 \mathrm{~kg}$ was identified as an outlier according to Grubbs' test (Grubbs, 1969) with a $P$-value less than 0.001 . The second and third automated weights for this individual were 460 and $461 \mathrm{~kg}$ respectively. The exclusion of this single outlier changed Lin's concordance correlation coefficient from 0.91 to 0.98 . The relationship between first automated weighing liveweights and static weight is displayed in
Figure 3. The proximity of data points to the line of perfect concordance was consistent across the weight range of the study population. Correlation coefficients for association between the difference and the mean were less than -0.18 for all 3 weighings.

The $95 \%$ limits of agreement plot for the first automated weighing is shown in Figure 4. The 95\% limits of agreement (automated minus static weights) were -39.2 to $71.2 \mathrm{~kg}$ and the mean difference was $16.0 \mathrm{~kg}$ $(\mathrm{SD}=28.2 \mathrm{~kg})$. The exclusion of the previously described automated outlier (automated weight $630 \mathrm{~kg}$ ) changed the $95 \%$ limits of agreement to -7.5 to 31.0 $\mathrm{kg}$ and the mean difference to $11.8 \mathrm{~kg}(\mathrm{SD}=9.8 \mathrm{~kg})$.

This clustering of differences within cows describes the extent to which individual cows record a consis-

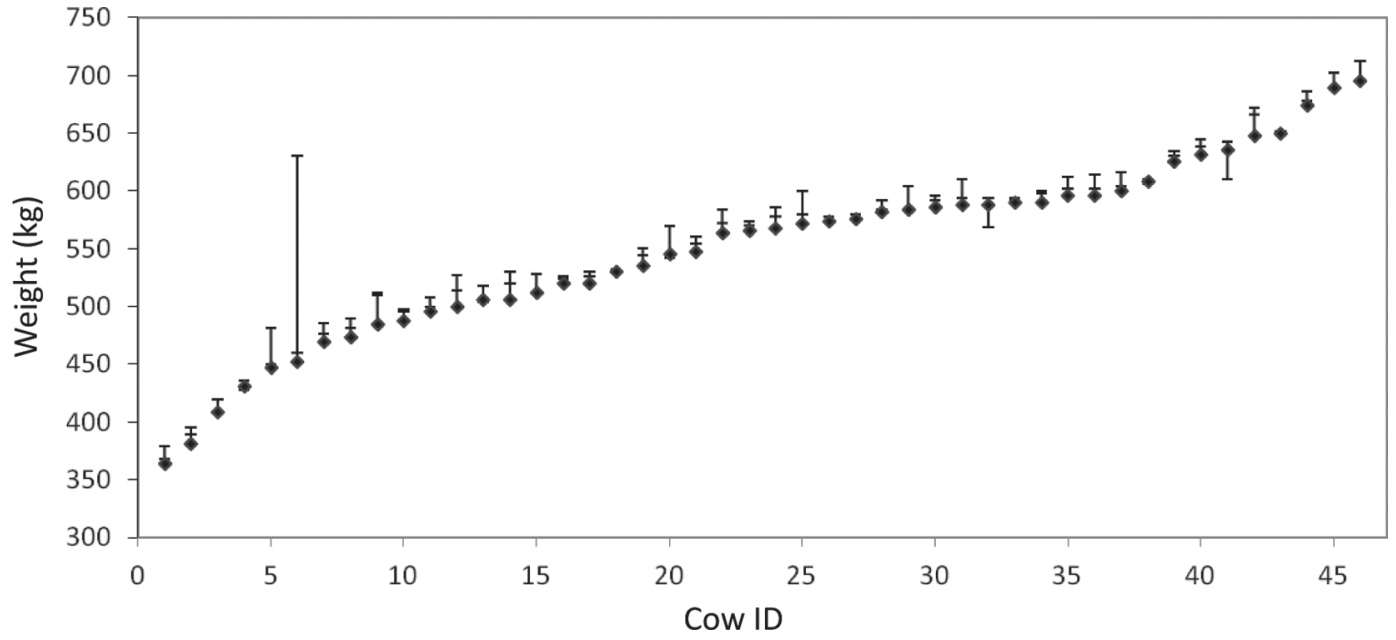

Figure 2. Automated and static weights for 46 cows. Error bars indicate the maximum and minimum automated weight recorded for each cow and the data point $($ ) indicates the cow's static weight. For cows whose minimum automated weight was greater than their static weight, both error bars are above the static weight. 
Table 1. Agreement and repeatability measures for all weights (static and automated) from 46 cows, all weights excluding a single outlier automated weight from 46 cows and weights from 44 cows after automated weights associated with misbehavior were removed

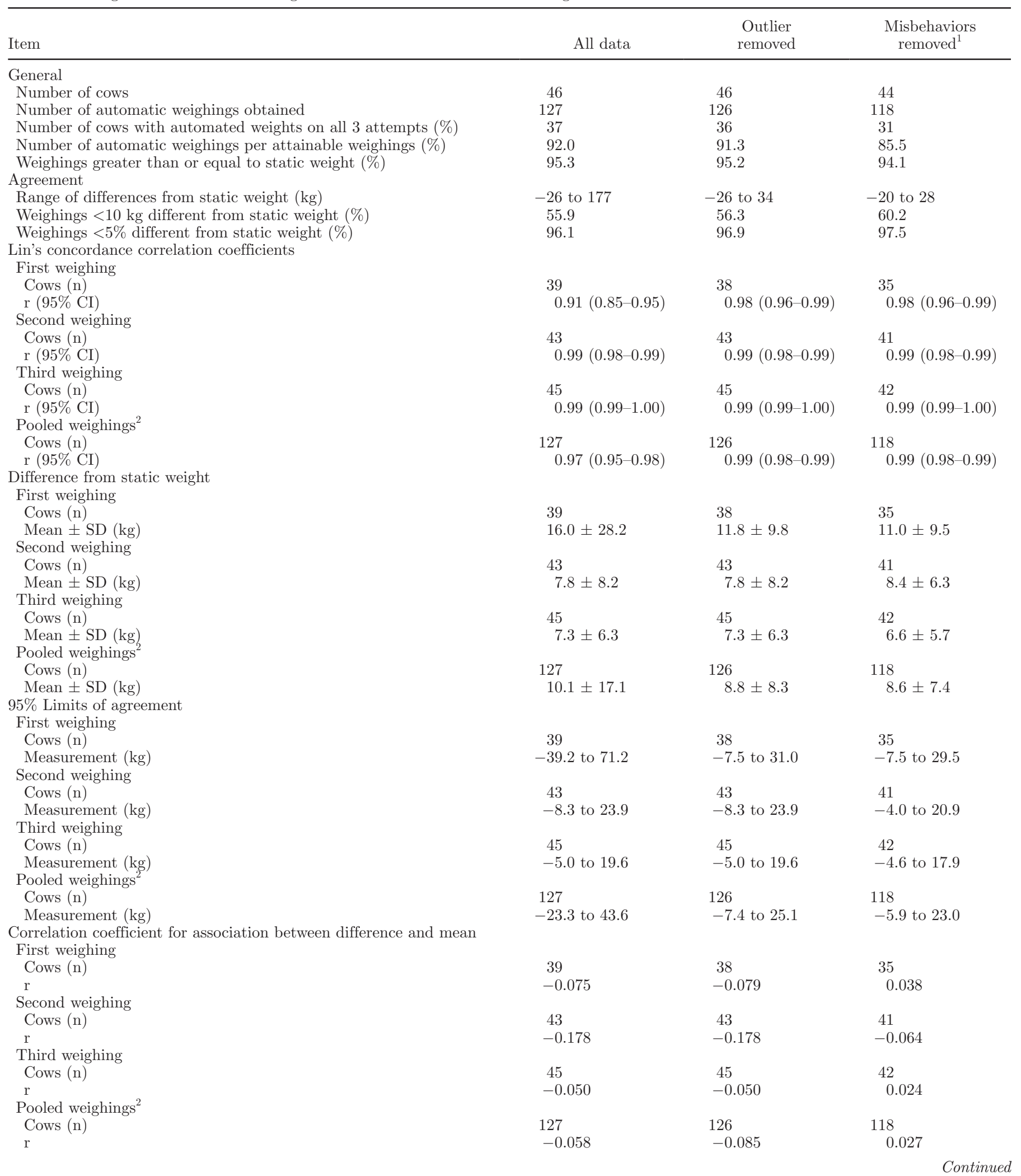


Table 1 (Continued). Agreement and repeatability measures for all weights (static and automated) from 46 cows, all weights excluding a single outlier automated weight from 46 cows and weights from 44 cows after automated weights associated with misbehavior were removed

\begin{tabular}{|c|c|c|c|}
\hline Item & All data & $\begin{array}{l}\text { Outlier } \\
\text { removed }\end{array}$ & $\begin{array}{l}\text { Misbehaviors } \\
\text { removed }^{1}\end{array}$ \\
\hline \multicolumn{4}{|l|}{ Repeatability } \\
\hline Range of absolute differences between automatic weights $(\mathrm{kg})$ & 0 to 170 & 0 to 32 & 0 to 28 \\
\hline $95 \%$ Repeatability coefficient $(95 \%$ CI) & $46.3(40.2-54.8)$ & $18.3(15.8-21.6)$ & $15.8(13.6-18.8)$ \\
\hline Cows with at least 2 identical automatic weights (\%) & 23.9 & 23.9 & 11.4 \\
\hline Weighings within $10 \mathrm{~kg}$ of automatic weight ${ }^{3}(\%)$ & 75.4 & 76.7 & 80.0 \\
\hline
\end{tabular}

${ }^{1}$ Including outlier.

${ }^{2}$ Not accounting for clustering of repeat weighings within cows.

${ }^{3}$ Differences calculated for each pair of automated weights within cow; cows with 3 automated weighing contributed 3 differences.

${ }^{4}$ Percentage differences calculated for each pair of automated weights within cow as absolute difference between 2 automated weights divided by their average.

tently higher, lower, or similar automated weight than the static weight when weighed repeatedly with the automated scales. Thirty-nine of 46 cows recorded all their automated weight readings higher than their static weight. Only 8 of 127 automated weights were lower than the corresponding static weight. The intraclass correlation coefficient, which assessed whether differences between automated and static weights were clustered within cows, was $0.06(95 \% \mathrm{CI}=0.00-0.51)$, providing little information about the extent of clustering. However, after excluding the 9 weighings associated with cow misbehavior, the intraclass correlation coefficient was $0.41(95 \% \mathrm{CI}=0.22-0.61)$, indicating that differences were clustered within cows.

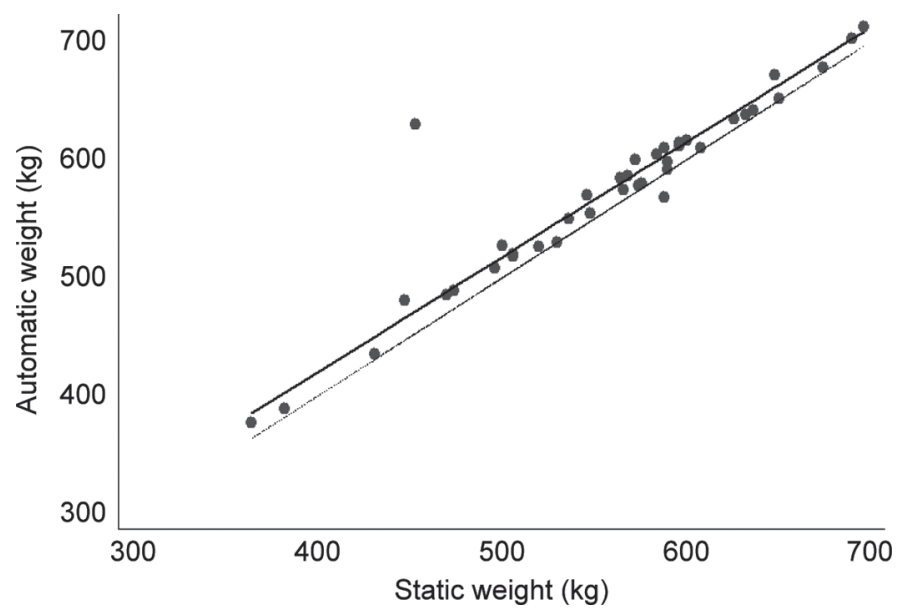

Figure 3. Relationship between liveweights from automated and static scales from the first automated weighing of 39 dairy cows. The $45^{\circ}$ line (slope of 1 ) through the intercept (the line of perfect concordance) and the line of best fit are shown as thin and thick lines, respectively.

\section{Repeatability}

The $95 \%$ repeatability coefficient for automated weighings was $46.3 \mathrm{~kg}(95 \% \mathrm{CI}=40.2-54.8 \mathrm{~kg})$. Removal of the single outlier described previously improved the repeatability coefficient to $18.3 \mathrm{~kg}(95 \% \mathrm{CI}$ $=15.7-21.4 \mathrm{~kg})$.

Automated weights for each cow were compared between one another as a measure of repeatability; 38 cows had weights at both their first and second attempts, 38 cows had weights at both their first and third attempts, and 42 cows had weights at both their second and third attempts, giving a total of 118 automated weight differences from a possible 138 differences. Absolute weight differences between pairs of automated weights varied from 0 to $170 \mathrm{~kg}$. Of the 118 automated weight differences, $75.4 \%$ were within $10 \mathrm{~kg}$ and $5.9 \%$ differed by

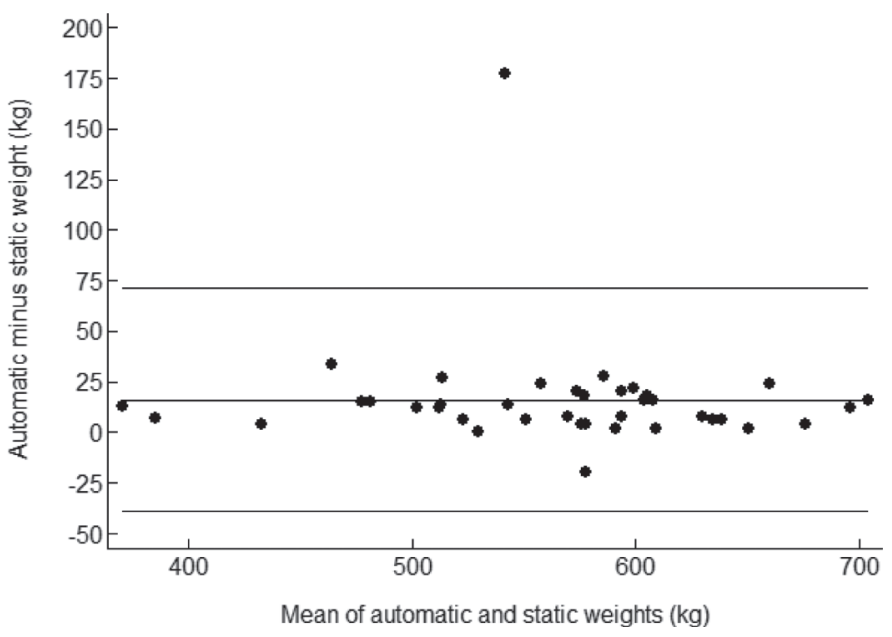

Figure 4. The $95 \%$ limits of agreement plot for liveweight differences between automated and static scales for the first automated weighing of 39 dairy cows. 
Table 2. Components of Lin's concordance correlation coefficient

\begin{tabular}{lcccc}
\hline $\begin{array}{l}\text { Automatic } \\
\text { weighing number }\end{array}$ & $\mathrm{n}$ & $\begin{array}{c}\text { Accuracy }^{1} \\
\left(\mathrm{C}_{\mathrm{b}} \text { coefficient }\right)\end{array}$ & $\begin{array}{c}\text { Precision } \\
(\mathrm{r})\end{array}$ & $\begin{array}{c}\text { Lin's concordance correlation } \\
\text { coefficient }\left(\mathrm{r} \times \mathrm{C}_{\mathrm{b}}\right)\end{array}$ \\
\hline 1 & 39 & 0.978 & 0.934 & 0.914 \\
2 & 43 & 0.994 & 0.994 & 0.989 \\
3 & 45 & 0.995 & 0.997 & 0.992 \\
Pooled $^{2}$ & 127 & 0.991 & 0.975 & 0.967 \\
\hline
\end{tabular}

${ }^{1} \mathrm{C}_{\mathrm{b}}$ is a bias correction factor that measures how far the best-fit line deviates from the $45^{\circ}$ line (measure of accuracy). No deviation from the $45^{\circ}$ line occurs when $C_{b}=1$ (Lin, 1989).

${ }^{2}$ Not accounting for clustering of repeat weighings within cows.

more than $20 \mathrm{~kg}$. In relative terms, $96.6 \%$ differed by less than $5 \%$ and $93.2 \%$ differed by less than $3 \%$.

\section{Effects of Cow Misbehavior}

Misbehaviors were observed for 9 (7.1\%) of the 127 automated weights. First lactation heifers contributed 7 of these 9 misbehavior weights. The analyses for agreement and repeatability were repeated on the data set excluding all automated weights associated with misbehavior. Results are summarized in Table 1. Improvements in all measures of agreement and repeatability were noted.

Of the 7 automated weight differences greater than $20 \mathrm{~kg}, 5$ were accounted for by cow misbehavior at one or both of the automated weighings. Similarly, 3 of 4 automated weight differences greater than $5 \%$ were associated with cow misbehavior.

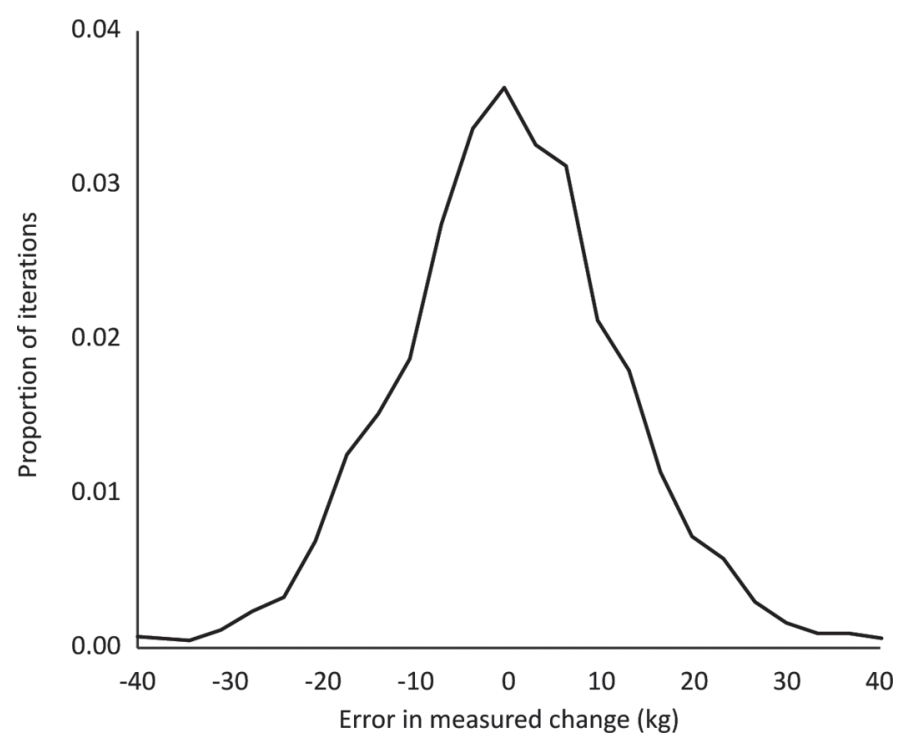

Figure 5. Simulated distribution of errors when assessing liveweight change within a cow, calculated as change in individual automated weighings. Differences between automated scale weight and true weight within the same cow when weighed repeatedly with the automated scales were assumed to be uncorrelated for these simulations. Errors were simulated using 2,000 iterations.

\section{Simulated Errors in Changes in Automated System Weights for Assessing Liveweight Change}

Results of simulations are shown in Figures 5 and 6 and Table 3. The extent of clustering of differences between automated scale weight and true weight within the same cow when weighed repeatedly with the automated scales was uncertain. After excluding the 9 weighings associated with cow misbehavior, the intraclass correlation coefficient for differences between automated and static scale weight was 0.41 . Accordingly, simulations were performed with coefficients for this correlation of, variously, $0,0.2$, and 0.4 . When the means of 7 weights were used rather than individual weights, the observed change in automated scale weights was within $10 \mathrm{~kg}$ of the actual weight change for at least $96 \%$ of comparisons, and errors were less if clustering was higher and when the single outlier described above was removed.

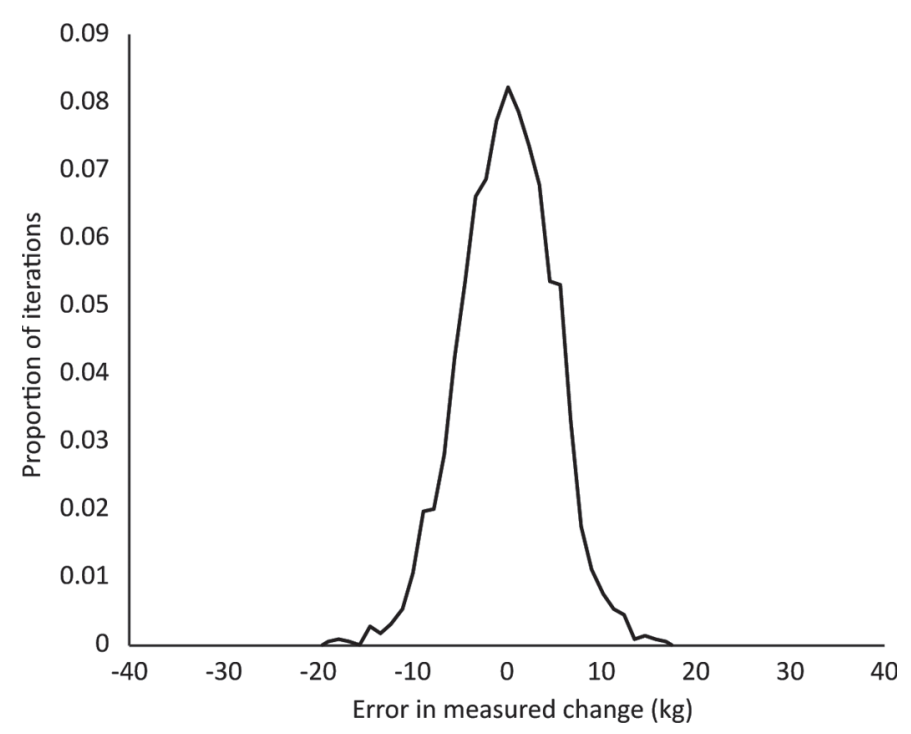

Figure 6. Simulated distribution of errors when assessing liveweight change within a cow, calculated as change between means of 7 automated weighings. Differences between automated scale weight and true weight within the same cow when weighed repeatedly with the automated scales were assumed to be uncorrelated for these simulations. Errors were simulated using 2,000 iterations. 
Table 3. Simulated distribution of errors (percentages of iterations within 5 and $10 \mathrm{~kg}$ of the actual weight change) when assessing liveweight change within a cow, calculated as changes in individual automated weights and changes between means of 7 weights for different correlations of differences between automated scale weight and true weight excluding a single outlier

\begin{tabular}{lcc}
\hline Magnitude of error & $\begin{array}{c}\text { Changes in individual automated } \\
\text { weights (excluding outlier) }\end{array}$ & $\begin{array}{c}\text { Changes in means of } 7 \text { weights } \\
\text { (excluding outlier) }\end{array}$ \\
\hline $\begin{array}{l}\text { Assuming no correlation }{ }^{1} \\
<5 \mathrm{~kg}\end{array}$ & $34(37)$ & $69(77)$ \\
$<10 \mathrm{~kg}$ & $61(64)$ & $96(98)$ \\
Assuming correlation of $0.2^{1}$ & 37 & 76 \\
$<5 \mathrm{~kg}$ & 65 & 98 \\
$<10 \mathrm{~kg}$ & 41 & 83 \\
Assuming correlation of $0.4^{1}$ & 71 & 99 \\
$<5 \mathrm{~kg}$ & & \\
$<10 \mathrm{~kg}$ & &
\end{tabular}

Errors in means of automated weight changes for groups of cows were relatively small. For a group of 20 cows, and using changes in single automated weights for each cow, the standard error of the mean of the changes for these 20 cows was $2.7 \mathrm{~kg}$. This reduced to 1.7 and $1.2 \mathrm{~kg}$ when group size increased to 50 and 100 cows, respectively. Errors were markedly reduced when changes in the means of 7 automated weights for each cow were used; in this case, the standard error of the mean of the changes for these 20 cows was $1.1 \mathrm{~kg}$, reducing to 0.7 and $0.5 \mathrm{~kg}$ when group size increases to 50 and 100 cows, respectively.

\section{DISCUSSION}

\section{Uses of Automated Walk-Over Weighing Systems}

It is important to effectively manage weight change in lactating dairy cows. Measures of changes in individual cow weight over particular stages of lactation can be used as a management tool in commercial dairy herds (van Straten et al., 2009). Based on our results, without identification and removal of extreme outliers, this automated weighing system is inadequate for detecting small changes in weight in individual cows (such as $10-15 \mathrm{~kg}$, or about $3 \%$ of a typical cow in this herd) using single weight measurements. However, implementation of a filtration method to remove extreme values and comparisons of means of multiple weights may allow this system to detect short-term (weekly), small changes in liveweight in individual cows.

Our results also indicate that automated weights can have minimal error when assessing mean liveweight change in groups of cows. Our results show that, provided group sizes are at least modest (20 or more) and changes in each cow's means of multiple weights are used, standard errors of the mean change for the group are relatively small.

\section{Agreement}

The automated scales showed a substantial level of agreement (McBride, 2005) with static scales demonstrated by Lin's concordance correlation coefficient for pooled weighings. This agreed with findings from a similar study (Alawneh et al., 2011). However, based on the width of Bland and Altman's 95\% limits of agreement together with the simulated errors when assessing liveweight change, automated scales would be inadequate for detecting changes in weight in individual cows over short periods of time (e.g., weekly). It is unlikely that cow size had any effect on the level of agreement of these automated scales given that the proximity of data points to the line of perfect concordance were distributed evenly across the weight range of the population.

Our results indicate that the automated weights were biased upwards, but that the extent of this bias (as measured by the mean difference from the static weight) decreased from weighing 1 to 3 . Given that the static weight was the final measurement taken, this bias may be due to loss of weight through urination and defecation over the duration of the 1-h study period. Cattle can lose $1.5 \%$ of BW within a 1-h period off feed and water (McKiernan et al., 2007) due to urination and defecation. Using data with removal of the outlier, the mean difference between weighing 1 and the static weight was $11.8 \mathrm{~kg}$. This equates to a mean difference from the static weight of $2.1 \%$ using the average of the automated weights at weighing 1 as the denominator. Based on these observations, the agreement between the automated and static scales may be best assessed using weights obtained at weighing 3 , the closest automated weighing in time to when the static weighing occurred.

\section{Repeatability}

The repeatability of the scales (assessed by the repeatability coefficient) was poor, but removal of the 
outlier improved repeatability. Together with the reduction in $95 \%$ limits of agreement after exclusion of the same outlier, this suggests that implementation of a filtration system to exclude outlier weights may allow the automated weighing system to be useful for detecting moderate changes in liveweight $(>5 \%)$ that may occur over a short time frame.

Poor repeatability accounted for a substantial portion of the limited agreement observed, but additional important sources of lack of agreement were observed. Bland and Altman (1999) suggest that, should the limits of agreement and repeatability coefficient be considerably different from one another, other factors are responsible for lowering the agreement between methods. It is possible that the other factors responsible may indeed be the upwards bias of the automated scales and the loss of gut fill over the duration of the study (as explained previously).

If it were possible to improve repeatability of these automated scales, the limits of agreement between the automated and static weights might be reduced substantially. This lack of repeatability may be due, in part, to the design and functionality of the automated weighing scales. The automated scales used in the current study contained load cells placed under the weighing platform within load bars. As cows traversed the platform, the weight of the cow bent the load cell and produced a change in electrical resistance between 2 points. This change in resistance is converted to a weight (Tru-test, 2012). Different models of these scales contain different numbers of load cells. It is possible that more load cells within a platform may increase the capability of the weighing system to generate a weight as close to true weight as possible. The platform used throughout this study contains only 2 load cells; therefore, models containing 4 load cells may provide higher repeatability. Accordingly, it might be useful to repeat this study using such a system. Additionally, it is possible that the algorithms set within the software for the walk-over weighing system are not accurately estimating certain weights from the dynamic, oscillating curve produced as the animal traverses the weighing platform. However, to rectify this potential source of error requires consultation with the private company Tru-test and investigation into the software written, which proved difficult and unrewarding.

\section{Effects of Cow Misbehavior}

Exclusion of weights associated with cow misbehavior resulted in improvements in Lin's concordance correlation coefficient, the $95 \%$ limits of agreement, and the $95 \%$ repeatability coefficient. However, not all automated weights associated with misbehavior were substantially different from the static weight; thus, despite the improvements observed, it would be unwise to filter weights based on behavioral observations alone, as weights close to the true value may be removed. Moreover, observational filtration would be impractical in a commercial dairy setting.

\section{Clustering}

After removal of misbehavior weights, the intraclass correlation coefficient suggested that the differences observed between each automated weight and the static weight of an individual were not random, and some cows yielded automated weights that were similarly different to the static weight at each weighing. It is possible that the gait with which certain cows traverse the weighing platform could result in automated weights that are repeatedly and reliably different from the true weight of those individuals. The simulated errors when assessing liveweight change suggested that uncertainty about the true value of the intraclass correlation coefficients are unlikely to be important in practical terms when the scales are used to detect differences of more than $10 \mathrm{~kg}$.

\section{Simulation Predictions}

Given that true changes in BW over several weeks postpartum are likely to be of the order of 20 to 100 kg (Buckley et al., 2003; Roche et al., 2007b), errors in changes in single automated weights for assessing actual liveweight change were substantial. Errors in changes in the means of 7 automated weights for assessing actual liveweight change were much smaller. The simulation results predicted that when differences between 2 weights are assessed using the mean of 7 weights rather than a single weight, errors are markedly reduced. This is consistent with a previous report by Alawneh et al. (2011), who concluded that averages of weights recorded over $7 \mathrm{~d}$ were preferable to single weights. The simulations also predicted that quite small mean changes in weight for groups of cows could be detected in moderate- to large-sized groups.

\section{CONCLUSIONS}

The automated walk-over weighing system showed substantial agreement with the static scales when assessed using Lin's concordance correlation coefficient. This contrasted with limited agreement when assessed using Bland and Altman's method, largely due to poor repeatability. This suggests that the automated weighing system is inadequate for detecting small liveweight differences in individual cows based on comparisons of single weights. Misbehaviors and other factors can 
result in the recording of spurious values on walk-over scales. Excluding outlier weights and comparing means of 7 consecutive daily weights may improve agreement sufficiently to allow meaningful assessment of small short-term changes in automated weights in individuals and groups of cows.

\section{ACKNOWLEDGMENTS}

The authors thank Dairy Australia (Melbourne, Australia), The Gardiner Foundation (Melbourne, Australia), the University of Melbourne, and the Warrnambool Veterinary Clinic. We also thank the staff and managers of the commercial dairy herd (Framlingham, Australia) for their contributions to this study.

\section{REFERENCES}

Alawneh, J. I., M. A. Stevenson, N. B. Williamson, N. Lopez-Villalobos, and T. Otley. 2011. Automatic recording of daily walkover liveweight of dairy cattle at pasture in the first 100 days in milk. J. Dairy Sci. 94:4431-4440.

Alawneh, J. I., M. A. Stevenson, N. B. Williamson, N. Lopez-Villalobos, and T. Otley. 2012a. The effect of clinical lameness on liveweight in a seasonally calving, pasture-fed dairy herd. J. Dairy Sci. 95:663-669.

Alawneh, J. I., M. A. Stevenson, N. B. Williamson, N. Lopez-Villalobos, and T. Otley. 2012b. The effect of liveweight change on reproductive performance in a seasonally calving, pasture fed dairy herd. Livest. Sci. 145:131-139.

Berry, D. P., F. Buckley, and P. Dillon. 2007a. Body condition score and liveweight effects on milk production in Irish Holstein-Friesian dairy cows. Animal 1:1351-1359.

Berry, D. P., J. M. Lee, K. A. Macdonald, and J. R. Roche. 2007b. Body condition score and body weight effects on dystocia and stillbirths and consequent effects on postcalving performance. J. Dairy Sci. 90:4201-4211.

Berry, D. P., J. M. Lee, K. A. Macdonald, K. Stafford, L. Matthews, and J. R. Roche. 2007c. Associations among body condition score, body weight, somatic cell count, and clinical mastitis in seasonally calving dairy cattle. J. Dairy Sci. 90:637-648.

Bland, J. M., and D. G. Altman. 1986. Statistical methods for assessing agreement between two methods of clinical measurement. Lancet 1(8476):307-310.

Bland, J. M., and D. G. Altman. 1990. A note on the use of the intraclass correlation coefficient in the evaluation of agreement between two methods of measurement. Comput. Biol. Med. 20:337-340.

Bland, J. M., and D. G. Altman. 1999. Measuring agreement in method comparison studies. Stat. Methods Med. Res. 8:135-160.

Buckley, F., K. O'Sullivan, J. F. Mee, R. D. Evans, and P. Dillon. 2003. Relationships among milk yield, body condition, cow weight, and reproduction in spring-calved Holstein-Friesians. J. Dairy Sci. $86: 2308-2319$.
Garnsworthy, P. C., K. D. Sinclair, and R. Webb. 2008. Pages 194-199 in BCVA Congress: Nutrition and Fertility in Cattle., Killarney, Ireland. Br. Cattle Vet. Assoc. (BCVA), London, UK.

Grubbs, F. E. 1969. Procedure for detecting outlying observations in samples. Technometrics 11:1-21.

Kottner, J., L. Audigé, S. Brorson, A. Donner, B. J. Gajewski, A. Hróbjartsson, C. Roberts, M. Shoukri, and D. L. Streiner. 2011. Guidelines for reporting reliability and agreement studies (GRRAS) were proposed. J. Clin. Epidemiol. 64:96-106.

Lin, L. 2008. Overview of agreement statistics for medical devices. J. Biopharm. Stat. 18:126-144.

Lin, L. I. 1989. A concordance correlation coefficient to evaluate reproducibility. Biometrics 45:255-268.

Lin, L. I. 2000. A note on the concordance correlation coefficient. Biometrics 56:324-325.

Lin, L. I.-K. 1992. Assay validation using the concordance correlation coefficient. Biometrics 48:599-604.

Macdonald, K. A., G. A. Verkerk, and J. W. Penno. 1999. Validation of body condition scoring by using ultrasound measurements of subcutaneous fat. Proc. N.Z. Soc. Anim. Prod. 59:177-179.

Maltz, E. 1997. The body weight of the dairy cow: III. Use for on-line management of individual cows. Livest. Prod. Sci. 48:187-200.

Maltz, E., S. Devir, J. Metz, and H. Hogeveen. 1997. The body weight of the dairy cow: I. Introductory study into body weight changes in dairy cows as a management aid. Livest. Prod. Sci. 48:175-186.

McBride, G. B. 2005. A proposal for strength-of-agreement criteria for Lin's concordance correlation coefficient. Page 6 in National Institute of Water \& Atmospheric Research Ltd., Auckland, New Zealand. Report for Ministry of Health, Hamilton, New Zealand.

McBride, G. B. 2007. Statistical Calculators; Lin's Concordance. Accessed Sep. 9, 2012. http://www.niwa.co.nz/online-services/ statistical-calculators/concordance.

McKiernan, B., B. Gaden, and B. Sundstrom. 2007. Dressing percentages for cattle. Pages 1-3 in Primefact 340. NSW Department of Primary Industries, Orange, Australia.

Morton, J. M. 2003. The incalf project-Identifying risk factors for reproductive performance in Australian dairy herds. Cattle Pract. 11:201-208.

Petrie, A., and P. Watson. 2006. Statistics for Veterinary and Animal Science. 2nd ed. Blackwell Publishing, Oxford, UK.

Roche, J. R., N. C. Friggens, J. K. Kay, M. W. Fisher, K. J. Stafford, and D. P. Berry. 2009. Body condition score and its association with dairy cow productivity, health, and welfare. J. Dairy Sci. 92:5769-5801.

Roche, J. R., J. M. Lee, K. A. Macdonald, and D. P. Berry. 2007a. Relationships among body condition score, body weight, and milk production variables in pasture-based dairy cows. J. Dairy Sci. 90:3802-3815

Roche, J. R., K. A. Macdonald, C. R. Burke, J. M. Lee, and D. P. Berry. 2007b. Associations among body condition score, body weight, and reproductive performance in seasonal-calving dairy cattle. J. Dairy Sci. 90:376-391.

Tru-test. 2012. Scales Training. Accessed Oct. 11, 2012. www.sheep. ee/files//Scales\%20Training.pdf.

van Straten, M., N. Y. Shpigel, and M. Friger. 2009. Associations among patterns in daily body weight, body condition scoring, and reproductive performance in high-producing dairy cows. J. Dairy Sci. 92:4375-4385 